\title{
Rating of perceived exertion and heart rate relative to ventilatory threshold in women
}

\author{
I. L. Swaine BSc PhD, J. Emmett BSc BA DLC MA*, D. Murty BA*, C. Dickinson DipHE* \\ and M. Dudfield BEd ${ }^{+}$ \\ School of Health Sciences, University of Sunderland, Sunderland, *Department of the Environment, University \\ of Northumbria, Newcastle-upon-Tyne and ${ }^{\dagger}$ Leeds Sports Development Unit, The Fitness Clinic, Leeds, UK
}

\begin{abstract}
Forty women took part in a study designed to investigate self-selected exercise intensity relative to ventilatory threshold during circuit weight training (CWT) and exercise-to-music (ETM) sessions. Subjects were assigned to one of two groups which were beginners (B) or habitual exercisers (HE) on the basis of their exercise habits. All subjects first underwent a laboratory cycle ergometer test involving a continuous incremental exercise protocol from which ventilatory threshold (VT) was determined using piecewise linear regression analysis. This point was expressed in terms of heart rate $\left(\mathrm{VT}_{\mathrm{HR}}\right)$ and rating of perceived exertion $\left(\mathrm{VT}_{\mathrm{RPE}}\right)$. These points were then compared with those determined during exercise training sessions (TRA $A_{\text {HR }}$ and TRA $A_{\text {REE }}$ respectively). The results showed that mean(s.d.) TRA $A_{\text {RE }}$ (13.5(1.1) was not significantly different to mean(s.d.) $\mathrm{VT}_{\mathrm{RPE}}(12.8(0.5) ; P>0.05)$ but that mean(s.d.) $V_{\text {HR }}\left(134.8(13.5)\right.$ beats min $\left.^{-1}\right)$ and TRA $_{\text {HR }}\left(154.9(12.0)\right.$ beats min $\left.^{-1}\right)$ were different $(P<0.05)$. Beginners trained at a significantly higher percentage above VT $_{H R}$ than habitual exercisers (118(3.1) versus $111(2.8) \% P<0.05)$. During CWT the mean(s.d.) TRA $A_{H R}$ for beginners (143.2(7.6) beats $\min ^{-1}$ ) was significantly. lower than that for habitual exercisers $(152.5(10.1)$ beats $\left.\min ^{-1} ; P<0.05\right)$, but not different during ETM $(P<0.05)$. When these TRA $A_{H R}$ values were expressed relative to an estimated maximum heart rate (EMHR) they represented $86.5 \%$ in ETM and $80.5 \%$ in CWT which were different $(P<0.05)$. These results suggest that regardless of habitual exercise level and training mode, these women selected a common intensity of effort that was compatible with the described RPE.
\end{abstract}

Keywords: rating of perceived exertion, heart rate, ventilatory threshold, exercise to music, circuit weight training

The most popular methods by which individuals can simply judge the level of their exercise intensity include: heart rate as a percentage of a measured or estimated maximum ${ }^{1}$; breathlessness and descriptions of ventilatory distress ${ }^{2,3}$; and rating of perceived exertion (RPE)

The use of heart rate as a method by which exercise intensity can be regulated is perhaps still the most

Address for correspondence: Dr I. L. Swaine, Exercise Physiology, De Montfort University Bedford, 37 Lansdowne Road, Bedford MK40 2BZ, UK widely used method and usually involves a 'target' heart rate. However, this system of exercise prescription involves some difficulty in measurement and has been found to be inaccurate in many individuals especially when the exercise involves combinations of arm and leg work ${ }^{5}$. This method usually involves exercising at a given percentage of an estimated maximal heart rate which introduces considerable error, especially in older habitual exercisers ${ }^{6}$. Furthermore, the range of suggested training heart rates does not take account of differences in the individual threshold of anaerobiosis, and adjustments are rarely made for subjects as they progress longitudinally through exercise programmes and experience improvement in fitness ${ }^{7}$. Nevertheless, these systems remain popular especially in training programmes involving women ${ }^{8}$.

The degree of breathlessness has been used as a guide to exercise intensity in prescription of training programmes ${ }^{3}$. However, this respiratory parameter is difficult to quantify and has not been systematically assessed for validity as a means of exercise prescription. Also, ventilation is known to be a poor index of exercise intensity in some groups of exercisers ${ }^{9}$. The monitoring of this indicator by a group leader requires great skill and is inappropriate in large groups.

The rating of perceived exertion (RPE) has recently regained attention as a simple and practical method for regulation of exercise level ${ }^{10}$. This method has been used in studies of exercise prescription ${ }^{11}$ and has been applied to the workplace ${ }^{12}$ and sports ${ }^{13}$. The effects of training upon RPE have been reported ${ }^{14}$ and different modes of exercise have been used to collect data in subjects with different levels of fitness ${ }^{15}$. More recently, the use of the RPE scale in production of previously estimated ratings of exertion during exercise has been assessed and found to provide a physiologically valid means of regulating exercise intensity ${ }^{10}$.

In addition to the advances in exercise regulation methods, research evidence suggests that exercise at or close to the individual anaerobic threshold in women will optimize the improvement in cardiorespiratory fitness while minimizing the discomfort associated with lactate accumulation during exercise $^{16}$. This concept has been applied to the RPE 
scale ${ }^{17,18}$ and has provided the basis for exercise prescription using RPE that may correlate with lactate accumulation ${ }^{19}$.

There is, however, an absence of data upon self-selected exercise intensity in individuals involved in group training programmes. This is especially the case for groups of women that include participants of different ages and habitual exercise levels particularly during different modes of exercise training. The RPE and heart rate relative to noninvasive indices of anaerobic threshold during self-selected exercise in these groups remains to be elucidated.

This study was planned to investigate the selfselected exercise intensity relative to the ventilatory threshold during different modes of exercise in groups which include participants of differing habitual exercise levels.

\section{Subjects and methods}

Forty women took part in this study. Their mean (range) age was 35.4 (17-48) years. All subjects were asked to perform a laboratory assessment and were then monitored during exercise training sessions. Ten subjects were ascribed to each of four groups. These were beginners (B) and habitual exercisers (HE) for either circuit weight training (CWT) or exercise to music (ETM). The beginners (B) were individuals who had not been involved in any regular exercise training for at least 5 years. The habitual exercisers (HE) were those who had attended the respective CWT or ETM exercise training sessions at least two to three times per week for at least 3 months.

The laboratory assessment involved a continuous incremental cycle ergometer test. During this test subjects cycled at 50 r.p.m. and the work rate was increased by $12.5 \mathrm{~W}$ each minute. There was a $2-\mathrm{min}$ warm-up during which subjects pedalled against an unloaded flywheel. The cycle ergometer was mechanically braked (Monark, Stockholm, Sweden). Throughout the cycle ergometer test measurements were taken of heart rate (HR) using a cardiometer (Cardionics, Stockholm, Sweden), oxygen consumption $\left(\dot{V} \mathrm{O}_{2}\right)$, carbon dioxide output $\left(\dot{V} \mathrm{CO}_{2}\right)$ and minute ventilation $\left(\dot{V}_{\mathrm{E}}\right)$ using an analysis system (Mijnhardt, Odijk, Netherlands) which incorporated infrared and paramagnetic analysers for $\dot{V} \mathrm{O}_{2}$ and $\dot{V} \mathrm{CO}_{2}$ respectively and a gas turbine for $\dot{V}_{\mathrm{E}}$ (Mijnhard). In addition subjects were asked to rate their exertion using the 15-point scale of Borg $(1961)^{4}$ at the end of each minute. The test was terminated when subjects described the exercise with an RPE of 16 or greater. Subjects were allowed to familiarize themselves with all equipment and procedures before the formal testing protocol.

Ventilatory threshold (VT) was determined using piecewise linear regression analysis of the plot of $\dot{V}_{\mathrm{E}} / \dot{V}_{\mathrm{O}_{2}}$ and $\dot{V}_{\mathrm{E}} / \dot{V}_{\mathrm{CO}_{2}}$ against $\mathrm{HR}$ or $\mathrm{RPE}$. The ventilatory threshold (VT) was defined as the point at which $\dot{V}_{\mathrm{E}} / \dot{V}_{\mathrm{O}_{2}}$ began to increase in the absence of an increase in $\dot{V}_{\mathrm{E}} / \dot{V}_{\mathrm{CO}_{2}}{ }^{20}$. This analysis allowed objective determination of the presence of a breakpoint in these relations, and has been fully investigated previously ${ }^{21}$.
The identified B and HE groups of subjects for each training mode were then assigned at random to training sessions of which there were either 15CWT or 12 ETM classes. These classes were typically of $45 \mathrm{~min}$ overall duration of which $20 \mathrm{~min}$ comprised vigorous continuous exercise. In the ETM sessions exercise involved callisthenic type routines such as marching, half-squats and arm raises which were usually incorporated into continuous sequences. CWT included step-ups, skipping and body-weight routines such as star jumps. These sessions also involved some resistance exercises using weights such as arm curls. The remaining $25 \mathrm{~min}$ in both types of training involved warm-up, mobility and flexibility routines from which data were not analysed. Both types of training were selected so that the contribution of arm versus leg work in each was approximately equal. Throughout these classes subjects had HR monitored using telemetry (Sport Tester; Polar Electronics, Kempele, Finland) and were asked to grade their RPE by verbal description upon presentation of the scale while exercising each minute.

The analysis of data involved group mean and standard error calculation and is reported as such in the text (mean(s.e.m.)). The laboratory and training means were compared using Student's paired $t$ test and group differences (beginners versus habitual exercisers and CWT versus ETM) were analysed using Student's unpaired $t$ test. The relative heart rate and RPE values (\%) were compared between groups using the Wilcoxon signed rank test.

\section{Results}

Mean(s.e.m.) values for all subjects $(n=40)$ are given in Table 1. The mean(s.e.m.) heart rate $\left(\mathrm{VT}_{\mathrm{HR}}\right)$ and rating of perceived exertion $\left(\mathrm{VT}_{\mathrm{RPE}}\right)$ at ventilatory threshold from the laboratory assessments were $134.8(0.18)$ and $12.8(0.1)$ beats $\min ^{-1}$ respectively. The mean(s.e.m.) self-selected training exertion rating $\left(T_{R A} A_{R P E}\right)$ was $13.5(0.2)$ which was not significantly different $(P>0.05)$ from that attained at ventilatory threshold in the laboratory. The mean(s.e.m.) TRA $_{\mathrm{HR}}$ was 154.9(1.9) beats min $^{-1}$ which was significantly different $(P<0.01)$ from the $\mathrm{VT}_{\mathrm{HR}}$ in the laboratory.

The mean values for each laboratory and either ETM or CWT training measures in beginners and habitual exercisers are given in Table 2. The comparison between beginners and habitual exercisers showed that mean(s.e.m.) values of $\mathrm{VT}_{\mathrm{RPE}}$ were not significantly different $(P>0.05)$ being $12.9(0.1)$ and 12.7(0.1) for groups $B$ and $\mathrm{HE}$ respectively. The $\mathrm{VT}_{\mathrm{HR}}$ was significantly higher $(P<0.01)$ in group $\mathrm{HE}$ at 141.6(2.9) beats $\min ^{-1}$ when compared with group $B$

Table 1. Laboratory and training measures for entire group

\begin{tabular}{lr}
\hline Age (years) & $35.4(1.3)$ \\
$\mathrm{VT}_{\mathrm{HR}}\left(\right.$ beats $\left.\min ^{-1}\right)$ & $134.8(2.1)$ \\
$\mathrm{VT}_{\mathrm{RPE}}$ & $12.8(0.1)$ \\
$\mathrm{TRA}_{\mathrm{HR}}$ (beats $\mathrm{min}^{-1}$ ) & $154.9(1.9)$ \\
$\mathrm{TRA}_{\mathrm{RPE}}$ & $13.5(0.2)$ \\
\hline
\end{tabular}

Values are mean(s.e.m.) 
RPE and HR in exercise training women: I. L. Swaine et al.

Table 2. Laboratory and training measures in beginners and habitual exercisers from ETM and CWT groups

\begin{tabular}{|c|c|c|c|c|c|c|c|c|}
\hline & \multicolumn{2}{|c|}{$V T_{H R}\left(\right.$ beats $\left.\min ^{-1}\right)$} & \multicolumn{2}{|c|}{$V T_{R P E}$} & \multicolumn{2}{|c|}{$T R A_{H R}\left(\right.$ beats $\min ^{-1}$ ) } & \multicolumn{2}{|c|}{$T R A_{R P E}$} \\
\hline & $B$ & $H E$ & $B$ & $H E$ & $B$ & $H E$ & $B$ & $H E$ \\
\hline ETM & $132.0(4.2)$ & $145.4(2.6)$ & $12.8(0.2)$ & $12.6(0.2)$ & $160.5(3.6)$ & $163.9(1.8)$ & $14.0(0.5)$ & $13.1(0.2)$ \\
\hline CWT & $124.3(2.1)$ & $137.9(5.0)$ & $13.1(0.2)$ & $12.8(0.2)$ & $143.2(2.4)$ & $152.5(3.2)$ & $13.6(0.3)$ & $13.3(0.4)$ \\
\hline Total & $128.2(2.4)$ & $141.6(2.9)$ & $12.9(0.1)$ & $12.7(0.1)$ & $151.9(2.9)$ & 158.2(2.2) & $12.5(0.8)$ & $13.2(0.2)$ \\
\hline
\end{tabular}

Values are mean(s.e.m.); $V_{H R}$, ventilatory threshold in terms of heart rate and $V_{R P E}$ in terms of rating of perceived exertion; TRA $A_{H R}$, exercise training session heart rate; $T_{R A} A_{R P E}$, exercise training session rating of perceived exertion; $B$, beginners; $H E$, habitual exercisers

which had a mean $\mathrm{VT}_{\mathrm{HR}}$ of 128.2(2.4) beats $\mathrm{min}^{-1}$. For the same groups the TRA $A_{\mathrm{HR}}$ was higher $(P<0.05)$ for habitual exercisers but TRA ${ }_{R P E}$ was not different $(P>0.005)$. When TRA $\mathrm{TR}_{\mathrm{HR}}$ was expressed as a percentage of $\mathrm{VT}_{\mathrm{HR}}$ this gave mean(s.e.m.) relative training heart rates of $118(3.1) \%$ for group B and $111(2.8) \%$ for the HE group, which were different $(P<0.05)$. In the same groups the mean(s.e.m.) relative training exertion ratings $\left(\mathrm{TRA}_{\mathrm{RPE}} / \mathrm{VT}_{\mathrm{RPE}}\right)$ were $107(3.2) \%$ and $104(2.8) \%$ for B and HE groups. These were not different $(P>0.05)$.

The comparison of ETM and CWT values showed similar differences to those for the entire group. In CWT the difference between groups $B$ and HE in $\mathrm{TRA}_{\mathrm{HR}}$ was 9.3 beats $\min ^{-1}(P<0.05)$. However, for the subjects involved in ETM training there was no significant difference in the mean(s.e.m.) $\mathrm{TRA}_{\mathrm{HR}}$ for groups $B$ and HE being 160.5(3.6) beats $\min ^{-1}$ and 163.9(1.8) beats $\min ^{-1}$. The extent to which $\mathrm{TRA}_{\mathrm{HR}}$ exceeded $\mathrm{VT}_{\mathrm{HR}}$ was significantly different $(P<0.05)$ for ETM compared with CWT (16.8(2.1) and 13.0(1.6)

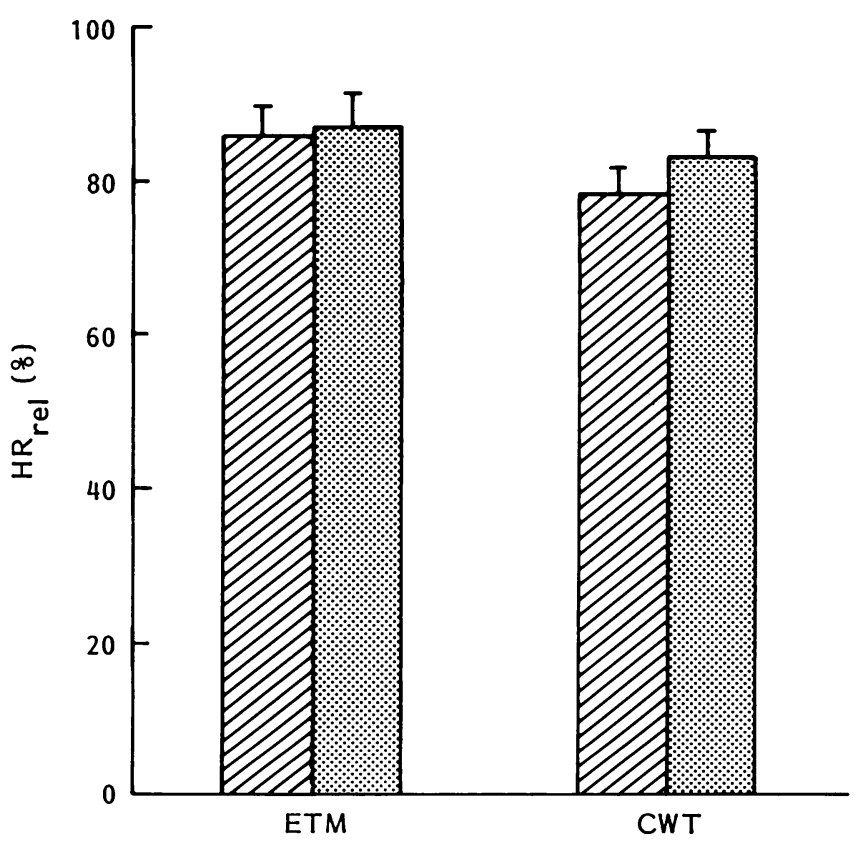

Figure 1. Mean TRA $A_{H R}$ relative to an estimated maximal heart rate (220 - age) (expressed as percentage) in beginners $(\mathbb{Z})$ and habitual exercisers (国) during two modes of exercise training: ETM, exercise to music; and $\mathrm{CWT}$, circuit weight training respectively). The $T R A_{H R}$ was also expressed relative to an estimated maximum (EMHR) which was computed using 220 - age (Reference 22) and is represented in Figure 1.

When expressed as a percentage this relative heart rate $\left(\mathrm{HR}_{\mathrm{rel}}\right)$ was higher in ETM than CWT $(P<0.05)$. The mean values for the two ETM groups were $86(2.2) \%$ for beginners and $87(3.0) \%$ for habitual exercisers. This corresponded to no difference $(P>0.05)$ in the mean(s.e.m.) TRA $A_{R P E}$ in beginners or habitual exercisers at 14(0.5) and 13.1(0.2). In contrast, for the CWT group the mean EMHR/TRA $\mathrm{HR}_{\mathrm{HR}}$ was higher $(P<0.05)$ in the HE group at $83(2.0) \%$ than in the B group at $78(2.2) \%$. As found in ETM there was no difference $(P>0.05)$ in mean(s.e.m.) $T_{R P A}$ values which were 13.6(0.3) and 13.3(0.3) for these groups.

\section{Discussion}

The laboratory assessments made on these subjects showed that the ventilatory threshold occurred at higher heart rates in habitual exercisers than beginners, but the rating of perceived exertion was not different. This confirms reports that suggest the relation of RPE and heart rate may be altered by training ${ }^{23}$. The higher $\mathrm{VT}_{\mathrm{HR}}$ in subjects with higher levels of fitness has been shown after cycling training ${ }^{14}$, and the results here provide supporting evidence for this observation in the two exercise modes investigated. The higher $\mathrm{VT}_{\mathrm{HR}}$ in habitual exercisers was evident in both circuit weight trainers and the exercise-to-music group.

Comparison of $\mathrm{TRA}_{\mathrm{HR}}$ and $\mathrm{VT}_{\mathrm{HR}}$ in the subjects of this study showed that during training the heart rates significantly exceeded those at VT in the laboratory. The difference between $\mathrm{VT}_{\mathrm{HR}}$ as determined using cycle ergometry and the TRA $\mathrm{HR}_{\mathrm{HR}}$ could be explained by the addition of arm exercise in the training programmes. This type of physical work is known to elevate heart rate ${ }^{24}$. Since the training involved combinations of arm and leg work in both ETM and CWT it would be expected that the heart rate during this exercise would exceed that determined during cycling in the laboratory. This does not explain the different degrees to which the $\mathrm{VT}_{\mathrm{HR}}$ was exceeded in the two different types of training since these modes of exercise had compatible contributions of arm and leg work. However, there would be some interruption to training during CWT as individuals moved from one exercise station to the next. This could 
account for the lesser extent to which $\mathrm{TRA}_{\mathrm{HR}}$ exceeded $\mathrm{VT}_{\mathrm{HR}}$ in this group.

The difference in $\mathrm{TRA}_{\mathrm{HR}}$ and $\mathrm{VT}_{\mathrm{HR}}$ was most pronounced in beginners involved in ETM. This would be attributable to the group training environment which might have encouraged competition or failed to offer appropriate alternative training levels for each individual. If this were the case then this would have important implications for group training sessions in ETM, emphasizing the requirement for lower intensity options and the inclusion of rest periods for beginners.

The use of heart rate and RPE during exercise training remains the focus of attention in exercise physiology research ${ }^{14}$. The relevance of the HR and RPE during training, particularly with reference to anaerobiosis during exercise, has remained confusing and often misleading ${ }^{10}$. The results provided here confirm that the use of heart rate during exercise training sessions can be misleading particularly when applied to groups of women of various ages involved in different activities, especially when these groups involve women of different habitual exercise levels. It appears that these individuals invariably select a level of exercise that corresponds to that described as 'moderately hard', particularly when applied to exercise sessions of 20-30-min duration. This would substantiate evidence suggesting that this exercise level equates to an individual level of anaerobics, above which the necessary vigour would be unsustainable due to lactate accumulation ${ }^{19}$.

It appears that the physiological response to anaerobiosis adequately limits exertion provided that the individual has the freedom to choose from a range of exercise levels and understands the rationale of the training programme. Adherence to heart rate targets especially when these are expressed relative to an estimated maximum based on age, may be misleading. This would particularly be the case during exercise-to-music training according to our results. Limiting the exercise heart rate during these sessions could compromise the training effect and provides further basis for less reliance on this parameter during these types of training. Perhaps less emphasis should be placed on strict adherence to heart rate targets by groups of individuals, and descriptive rating of exertion be adopted in preference. Ideally, both heart rate and perceived exertion could be monitored if necessary. Furthermore, it would also appear that the use of exercise involving small muscle-group work (CWT) did not distort the perception mechanism which enables selection of appropriate levels of exercise training.

In conclusion, the results from this study support those of other investigations involving RPE during exercise training ${ }^{25}$. Previous reports have presented data for RPE during various forms of exercise ${ }^{26}$. These studies have also investigated the production of RPE levels during exercise ${ }^{10}$. Almost all of these reports have used male subjects and there has been little evidence of RPE and heart rate during exercise training sessions. The results here add further substance to the merits of RPE in exercise prescription especially for women involved in group training sessions.

\section{References}

1 American College of Sports Medicine Position Stand. The recommended quantity and quality of exercise for developing and maintaining cardiorespiratory and muscular fitness in healthy adults. Med Sci Sports Exerc 1990; 22: 265-74.

2 Pengelly LD, Rebuck AS, Campbell EJM, eds. Loaded Breathing. Ontario, Canada: Longman, 1974.

3 Adams L, Guz A. Dyspnoea on exertion. In: Whipp BJ, Wasserman K, eds. Exercise Pulmonary Physiology and Pathophysiology. Basel, Switzerland: Marcel Decker. 1991; 52.

4 Borg G. Interindividual scaling and perception of muscular force. Kungliga Fysiografiska Saliskapets: Lund Forhandlinger 1961; 31: 117-25.

5 Gamberele F. Perceived exertion, heart rate, oxygen uptake and blood lactate in different work operations. Ergonomics 1972; 15: 545-54.

6 Jones NL, Campbell EJM. Clinical Exercise Testing, 2nd ed. Philadelphia, Pennsylvania, USA: W. B. Saunders, 1982.

7 Davis JA, Frank MH, Whipp BJ, Wasserman K. Anaerobic threshold alterations caused by endurance training in middle aged men. J Appl Physiol 1979; 46: 1039-46.

8 Egger G, Champion N. The Fitness Leaders Handbook Kenthurst, Australia: Kangaroo Press, 1990.

9 Powers SK, Dodd S, Garner, R. Precision of ventilatory and gas exchange alterations as a predictor of the anaerobic threshold. Eur J Appl Physiol 1984; 52: 173-7.

10 Dunbar CC, Robertson RJ, Baun R, Blandin MF et al. The validity of regulating exercise intensity by ratings of perceived exertion. Med Sci Sports Exerc 1992; 24: 94-9.

11 Noble BJ. Clinical applications of perceived exertion. Med Sci Sports Exerc 19.32; 14: 406-11.

12 Asfour SS, Ayoub MM, Mital A. Perceived exertion of physical effort for various manual handling tasks. Am Ind Hyg Assoc J 1983; 44: 223-8.

13 Eston RG, Davies BL, Williams TG. Use of perceived effort ratings to control exercise intensity in young healthy adults. Eur J Appl Physiol 1987; 56: 222-4.

14 Hill DW, Cureton KJ, Grisham SC, Collins MA. Effect of training on the rating of perceived exertion at the ventilatory threshold. Eur J Appl Physiol 1987; 56: 206-11.

15 Berry MJ, Weyrich AS, Robergs RA, Krause KM, Ingalls CP. Ratings of perceived exertion in individuals with varying fitness levels during walking and running. Eur J Appl Physiol 1989; 58: 494-9.

16 Gibbons ES, Jessup GT, Wells TD, Werthmann DA. Effects of various training intensity levels on anaerobic threshold and aerobic capacity in females. J Sports Med Phys Fitness 1983; 23: 315-8.

17 Purvis JW, Cureton KJ. Ratings of perceived exertion at the anaerobic threshold. Ergonomics 1981; 24: 295-300.

18 Demello JJ, Cureton KJ, Boineau RE, Singh MM. Ratings of perceived exertion at the lactate threshold in trained and untrained men and women. Med Sci Sports Exerc 1987; 19: 354-62.

19 Borg G, Hassmen P, Lagerstrom M. Perceived exertion related to heart rate and blood lactate during arm and leg exercise. Eur J Appl Physiol 1987; 56: 679-85.

20 Caiozzo VJ, Davis JA, Ellis JF, Azus JL et al. A comparison of gas exchange indices used to detect the anaerobic threshold. J Appl Physiol 1982; 53: 1184-9.

21 Orr GW, Green HJ, Hughson RL, Bennett GW. A computer linear regression model to determine ventilatory anaerobic threshold. J Appl Physiol 1982; 52: 1349-52.

22 Astrand PO, Rodahl K. Textbook of Work Physiology. New York, USA: McGraw-Hill, 1977: 346-7.

23 Gutmann MC, Squires RW, Pollock ML, Foster C, Anholm J. Perceived exertion-heart rate relation during exercise testing and training in cardiac patients. Journal of Cardiac Rehabilitation 1981; 1: 52-9.

24 Stenberg JB, Astrand PO, Ekblom B, Royce J, Saltin B. Haemodynamic response to work with different muscle groups in sitting and supine. J Appl Physiol 1967; 22: 61-72.

25 Birk TJ, Birk CA. Use of ratings of perceived exertion for exercise prescription. Sports Med 1987; 4: 1-8.

26 Fleishman EA, Gebhardt DL, Hogan JC. The perception of physical effort in job tasks. In: Borg $G$, Ottoson $D$, eds. The Perception of Exertion in Physical Work. London, UK: Macmillan Press, 1986: 225-42. 